\title{
Circadian variation in disease activity in rheumatoid arthritis
}

\author{
J A L HARKNESS, M B RICHTER, G S PANAYI, K VAN DE PETTE, A UNGER, R POWNALL, \\ $M$ GEDDAWI
}

\begin{abstract}
Disease activity in rheumatoid arthritis as measured by repeated estimation of joint pain, stiffness, articular index, and grip strength was shown to have a circadian rhythm, maximal activity being seen between 0200 and 0400 and minimal activity in the early afternoon. This variation in disease activity may be related to circadian alterations in immune and inflammatory responses (such as immune complexes and neutrophil function) dependent on alterations in circulating concentrations of steroids.
\end{abstract}

The circadian variation in disease activity has important implications in assessment of patients, prescription of drugs, and performance of drug trials.

\section{Introduction}

Rheumatoid arthritis is characterised by immunological abnormalities such as hypergammaglobulinaemia, the presence of immune complexes and rheumatoid factors in the serum, and lymphocytic infiltration of the synovial membrane. The activity of certain immune processes varies with the time of day or night at which it is observed. The reaction to intradermal tuberculin ${ }^{1}$ is an example of an immune response which shows pronounced circadian variation, and the time of rejection of renal allografts may be influenced by this." In rheumatoid arthritis immune responses to an as yet unidentified stimulus may be important in the expression of disease. ${ }^{3}$ Many symptoms and signs of active rheumatoid arthritis are worse at night or around the time of waking, and objective measurements have confirmed a diurnal variation in joint stiffness, hand volume, and grip strength ${ }^{5}{ }^{6}$; also a circadian rhythm in signs and symptoms was suggested by a recent outpatient investigation. ${ }^{7}$

We decided to investigate further the possibility of a circadian rhythm of disease activity in rheumatoid arthritis and see whether it was due to variations in immune processes, some of which vary in a circadian pattern in healthy people and reportedly occur in various immunological disorders but not, to our knowlcdge, studied in rheumatoid arthritis. ${ }^{7} 8$

Guy's Hospital Medical School, London SE1 9RT

J A L HARKNESS, MB, FRACP, research registrar in rheumatology

M B RICHTER, MB, FRACP, clinical researcher, department of medicine

G S PANAYI, MD, MRCP, professor of rheumatology

$K$ VAN DE PETTE, MB, MRCP, registrar in haematology

A UNGER, PHD, research associate, department of medicine

Chronotherapeutics Research Group, Renal Unit, City Hospital, Nottingham NG5 1PB

R POWNALL, PHD, senior research officer

Clinical Research Department, Schering AG, D-1000 Berlin 65, W Germany

M GEDDAWI, DSC, clinical associate

\section{Patients and methods}

We selected for the study 10 inpatients with classic or definite rheumatoid arthritis ${ }^{9}$ being treated with strict bed rest-but allowed to sit up-for generalised disease activity. Six were men and four women, and their mean age was 54.6 years (range 33-76). All were taking a non-steroidal anti-inflammatory drug-indomethacin (six), naproxen (one), ibuprofen (one), benorylate (one), flurbiprofen (one) -five were taking penicillamine, and one was receiving weekly gold injections. None was taking corticosteroids or hypnotics.

Assessment of disease activity-Patients were studied over 24 hours. Each patient was assessed clinically and a blood sample taken at 0600 , $0800,1200,1800$, and 2300. Pain and stiffness were each scored subjectively according to an arbitrary scale of severe (3), moderate (2), mild (1), and absent (0). A modified Ritchie articular index ${ }^{10}$ was used to assess joint tenderness, and grip strengths were measured with a sphygmomanometer bag inflated to $30 \mathrm{~mm}$ of mercury.

Laboratory assessments-Laboratory measurements in serum samples stored at $-70 \mathrm{C}$ were: C-reactive protein by single radial immunodiffusion, ${ }^{11}$ immune complexes by liquid-phase Clq-binding assay, ${ }^{12}$ and IgM rheumatoid factor by an enzyme-linked immunoassay. ${ }^{13}$ White cell counts in peripheral blood were obtained with a Coulter model S-Plus, and neutrophil and lymphocyte counts from a 500-cell differential. Plasma cortisol concentrations were assayed by a modified Mattingly technique. ${ }^{14}$

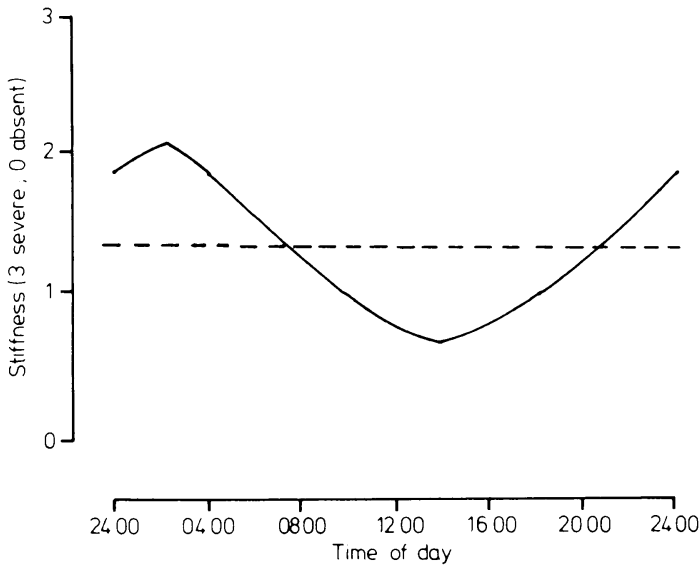

FIG 1 -Circadian rhythm of joint stiffness. (Mesor 1.35 . Amplitude 0.67. Peak time 0207. Peak value 2.02. Circadian variation $99 \%$ )

\section{Results}

Variations in clinical and laboratory measurements were seen during the observation period. The table shows these changes in the 10 patients studied for those variables which showed a significant circadian periodicity when analysed statistically (see below).

Clinical assessments-All measurements showed variations throughout the study period, with pain, stiffness, and articular index each showing maximal disease activity at around the time of waking and grip strength being inversely related. Analysis of the variations by the single and group rhythm analytical techniques of Nelson $e t a l^{15}$ defined significant circadian rhythms $(p<0.05)$ of joint stiffnes and grip strength only. Figures 1 and 2 show that the best-fitting sine wave representing disease activity had its maximum between 0200 and 0400 and its minimum at about 1600 . 
Laboratory assessments-Variations were seen in all measurements. Analysis of sine waves, however, showed that only the C1q-binding assay, peripheral blood neutrophil count, and plasma cortisol concentration had demonstrable significant circadian rhythms $(\mathrm{p}<0.05)$, with the variations in peripheral blood lymphocyte counts just failing to reach statistical significance. Figures 3,4 , and 5 show that the peak of the sine wave representing Clq-binding activity occurred at about 0800 and that the wave for peripheral blood neutrophil count bore a close inverse relation to those for disease activity, being lowest at about 0200 and maximal at about 1400. Plasma cortisol concentrations showed the usual circadian rhythm, with the peak between 0800 and 0900 . causes an increase in the fluid content of joint tissues. ${ }^{56}$ This does not, however, explain the variation seen in our patients, who were confined to bed day and night with little change in mobility. This mechanism would not account for the progressive worsening of symptoms observed during the afternoon and evening. Another explanation is that there is an important circadian variation in inflammatory processes. We observed significant variations in peripheral blood neutrophil counts, similar to those reported by other workers, and also noted that immune complexes vary during the 24 hours. Corticosteroid affects immune processes in several ways, ${ }^{16}$ including impaired

Variation with time of joint stiffness, grip strength, C1q-binding, and plasma cortisol concentrations in 10 patients with rheumatoid arthritis

\begin{tabular}{|c|c|c|c|c|c|c|c|c|c|c|c|}
\hline \multirow{2}{*}{ Time } & \multicolumn{10}{|c|}{ Case No } & \multirow{2}{*}{ Mean } \\
\hline & 1 & 2 & 3 & 4 & 5 & 6 & 7 & 8 & 9 & 10 & \\
\hline \multicolumn{12}{|c|}{ Foint-stiffness score ( 3 severe; 0 absent $)$} \\
\hline 0600 & 2 & 2 & 2 & 1 & 2 & 2 & 3 & 1 & 2 & 3 & $2 \cdot 0$ \\
\hline 0800 & 2 & 2 & 1 & 1 & 1 & 1 & 1 & 0 & 1 & 2 & 1.2 \\
\hline 1200 & 3 & 2 & 0 & 0 & 1 & 0 & 1 & 0 & 1 & 1 & 0.9 \\
\hline 1800 & 1 & 2 & 1 & 1 & 1 & 0 & 2 & 0 & 2 & 2 & $1 \cdot 2$ \\
\hline 2300 & $i$ & 2 & 2 & 2 & 2 & 2 & 2 & 0 & 2 & 2 & 1.7 \\
\hline \multicolumn{12}{|c|}{ Grip strength $(\mathrm{mm} \mathrm{Hg})$} \\
\hline 0600 & $\begin{array}{l}230 \\
315\end{array}$ & $\begin{array}{l}270 \\
290\end{array}$ & $\begin{array}{l}135 \\
150\end{array}$ & 105 & $>600$ & 135 & 270 & 300 & 215 & 70 & 233 \\
\hline 1200 & 310 & 280 & 170 & $\begin{array}{l}105 \\
95\end{array}$ & $\begin{array}{r}600 \\
600\end{array}$ & 205 & 335 & $\begin{array}{l}330 \\
360\end{array}$ & 230 & 160 & 272 \\
\hline 1800 & 480 & 290 & 150 & $\begin{array}{l}90 \\
120\end{array}$ & $\begin{array}{l}>600 \\
>600\end{array}$ & 195 & $\begin{array}{l}310 \\
310\end{array}$ & $\begin{array}{l}360 \\
340\end{array}$ & 240 & 170 & 273 \\
\hline \multirow{2}{*}{\multicolumn{12}{|c|}{105 C1q-binding }} \\
\hline & & & & & & & & & & & \\
\hline 0600 & $23 \cdot 3$ & $7 \cdot 7$ & $47 \cdot 0$ & $68 \cdot 1$ & 10.4 & $12 \cdot 1$ & $23 \cdot 6$ & $70 \cdot 0$ & $10 \cdot 9$ & $10 \cdot 7$ & $28 \cdot 4$ \\
\hline 0800 & 21.5 & $5 \cdot 7$ & $43 \cdot 2$ & $71 \cdot 1$ & 13.5 & $11 \cdot 1$ & $23 \cdot 8$ & $81 \cdot 0$ & $7 \cdot 8$ & $9 \cdot 7$ & $28 \cdot 9$ \\
\hline 1200 & $16 \cdot 5$ & $4 \cdot 2$ & $45 \cdot 3$ & $70 \cdot 8$ & $10 \cdot 5$ & $9 \cdot 9$ & 21.5 & $73 \cdot 0$ & $8 \cdot 6$ & $11 \cdot 1$ & $27 \cdot 1$ \\
\hline 1800 & 18.6 & $6 \cdot 9$ & $44 \cdot 2$ & 63.8 & 9.9 & $9 \cdot 9$ & $20 \cdot 2$ & $72 \cdot 0$ & $8 \cdot 1$ & 11.0 & $26 \cdot 5$ \\
\hline \multirow{2}{*}{\multicolumn{12}{|c|}{$\begin{array}{cc}10 \cdot 7 & 7 \cdot 2 \\
\text { Plasma cortisol } & (\mathrm{nmol} / \mathrm{l})\end{array}$}} \\
\hline & & 106 & 507 & & & & & & & & \\
\hline 0800 & 264 & 138 & 395 & 482 & $\begin{array}{l}444 \\
459\end{array}$ & 697 & $\begin{array}{l}697 \\
475\end{array}$ & $\begin{array}{r}81 \\
212\end{array}$ & $\begin{array}{l}222 \\
396\end{array}$ & $\begin{array}{l}491 \\
399\end{array}$ & $\begin{array}{l}447 \\
392\end{array}$ \\
\hline 1200 & 253 & 96 & 502 & 423 & 975 & 494 & 450 & 104 & 399 & 213 & 391 \\
\hline 1800 & 135 & 50 & 182 & 514 & 306 & 243 & 444 & 107 & 197 & - & 218 \\
\hline 2300 & 57 & 45 & 266 & 459 & 137 & 184 & 380 & 55 & 71 & 64 & 172 \\
\hline
\end{tabular}

Conversion: SI to traditional units-Plasma cortisol: $1 \mathrm{nmol} 1 \approx 0.04 \mu \mathrm{g} / 100 \mathrm{ml}$.

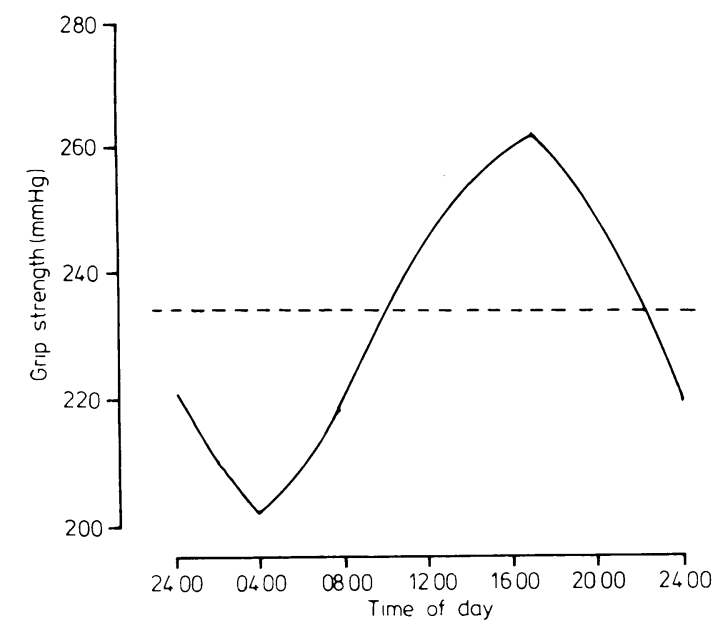

FIG 2-Circadian rhythm of grip strength. (Mesor 234 Amplitude 29. Peak time 1629. Peak value 263. Circadian variation $25 \%$ )

\section{Discussion}

We have confirmed the observations of Kowanko et al ${ }^{7}$ and agree with their suggestion that there is a circadian rhythm of disease activity in rheumatoid arthritis, manifested by joint stiffness and grip strength, which is estimated to be maximal between 0200 and 0400 and minimal at about 1600, though some method of assessment during sleep is needed to confirm that this is an observed maximum as well as a calculated one.

What is the mechanism of this circadian rhythm? The simplest explanation is that the immobility of patients at night

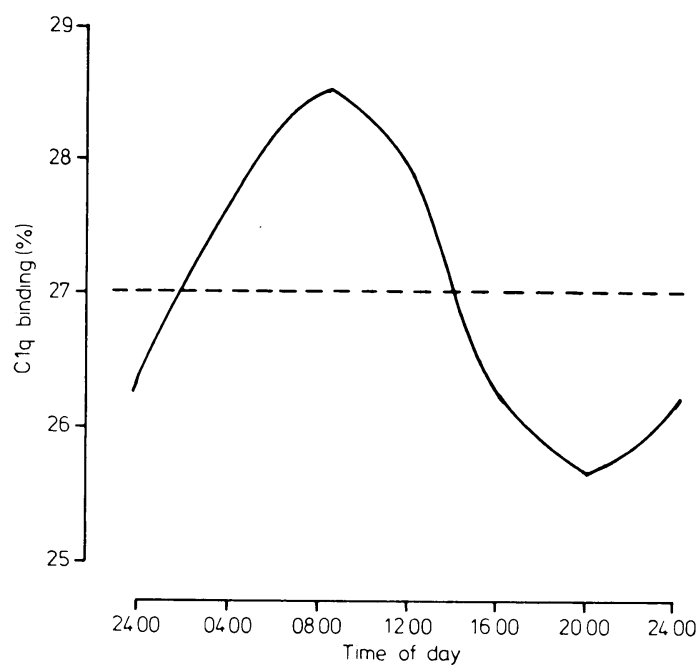

FIG 3-Circadian rhythm of Clq-binding assay. (Mesor 27. Amplitude 1.4. Peak time 0807. Peak value 28.4. Circadian variation $10 \%$ ).

migration of neutrophils and monocytes to inflammatory foci; transient reduction in circulating lymphocytes, monocytes, and eosinophils; transient neutrophil leucocytosis; impaired macrophage function; endothelial stabilisation; and effects on immunoglobulin production. Furthermore, Pownall and Knapp and colleagues showed that some of these interrelations vary with the time of day. ${ }^{17}$

Suppression of lymphocytes and monocytes and stimulation of neutrophils occurs maximally four to six hours after intravenous injection of hydrocortisone. ${ }^{16}$ Hence the natural variations 
in endogenous plasma cortisol, as observed in our patients, probably influence the activity of immune processes and the expression of disease activity in rheumatoid arthritis. When plasma cortisol was viewed in relation to stiffness and grip strength (fig 6) the sine wave representing disease activity was seen to be minimal about six hours after the natural peak of plasma cortisol, coinciding with the time of maximal corticosteroid effect on cells included in the inflammatory process. A similar inverse relation between endogenous corticosteroid and a delayed hypersensitivity-type reaction to oxazolone was reported in rats. ${ }^{18}$

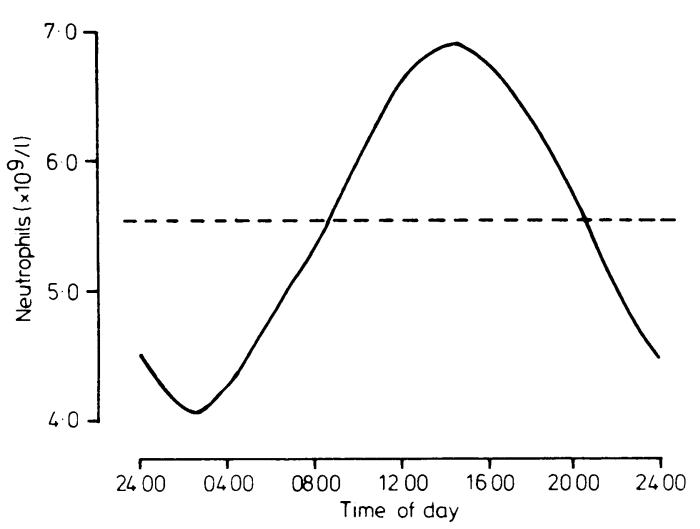

FIG 4-Circadian rhythm of neutrophil count. (Mesor 5.58. Amplitude 1.35. Peak time 1407. Peak value 6.92. Circadian variation $48^{\circ}$.)

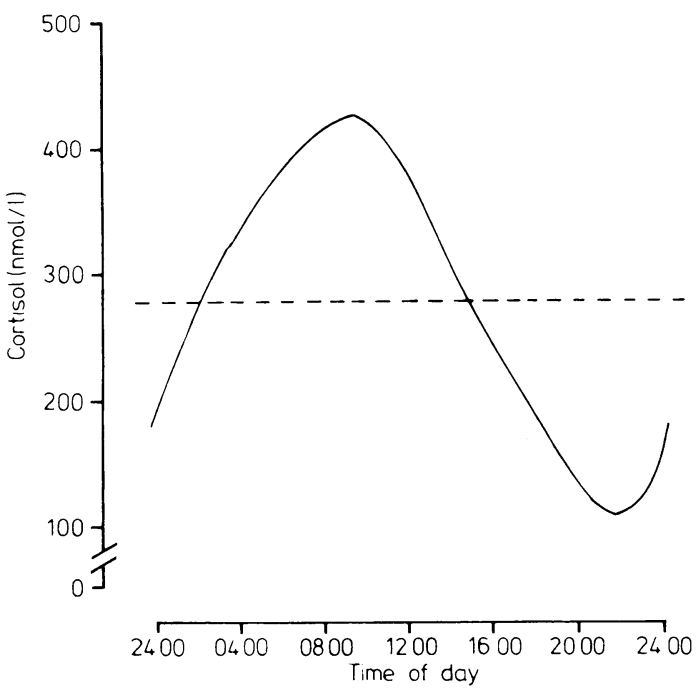

FIG 5-Circadian rhythm of plasma cortisol concentrations. (Mesor 277. Amplitude 149. Peak time 0800. Peak value 426. Circadian variation $(108 \%$..)

Conversion: SI to traditional units-Plasma cortisol: 1 $\mathrm{nmol} / 1 \approx 0.04 \mu \mathrm{g} / 100 \mathrm{ml}$.

Studies showing pronounced circadian variations have important clinical implications. Firstly, the time of day must be considered when making clinical assessments, because for patients seen in the early afternoon disease activity is likely to be underestimated. Secondly - for example, during drug trialsclinical assessments at different times of day may invalidate results or at best reduce the ability to detect change. Furthermore, the circadian variations in disease activity may result in misinterpretation when the apparent improvement from shortacting drugs may be due to the natural decrease in symptoms. Thirdly, they call into question the whole concept of prescribing drugs based on their pharmacokinetic properties alone, whichin the case of indomethacin, for example-may vary significantly with the time of administration. ${ }^{19}$ Giving a non-steroidal antiinflammatory drug to patients in the late evening is usually effective in reducing morning symptoms. It is, perhaps, not surprising that a study investigating the best times to give flurbiprofen found that missing either a morning or lunchtime dose of a short-acting non-steroidal anti-inflammatory drug, when natural improvement is occurring in most patients, had no measurable effect on disease activity. ${ }^{?}$

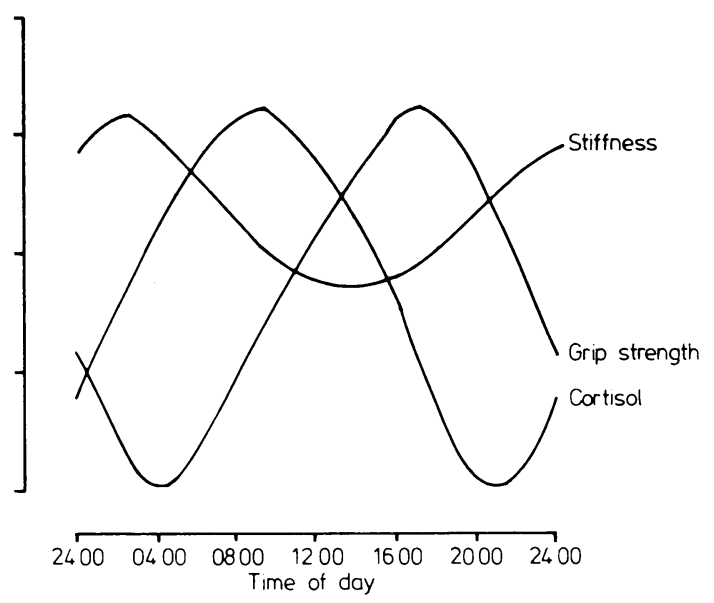

FIG 6-Circadian rhythms of stiffness and grip strength in relation to plasma cortisol concentrations.

We agree with Halberg, Reinberg, Knapp, and others who have studied circadian rhythms, and their influence on pharmacology and therapeutics, ${ }^{20}$ that less effort should be spent on the frequent changing of a patient's drug treatment and more on the dosage and timing of administration to achieve best control of the symptoms of disease. These principles seem relevant to the use of non-steroidal anti-inflammatory drugs in rheumatoid arthritis, as many doctors respond to a lack of response by changing the drug when a change in timing might be more effective.

We thank Dr R Grahame and Dr T Gibson for allowing us to study some of their patients. We are grateful to Dr M Knapp for valuable advice and criticism during the writing of the paper. The study was financed by a programme grant from the Arthritis and Rheumatism Council.

\section{References}

${ }^{1}$ Cove-Smith JR, Kabler P, Pownall R, Knapp MS. Circadian variation in an immune response in man. $B r$ Med $\mathcal{F} 1978 ;$ ii :253-4.

${ }^{2}$ Knapp MS, Cove-Smith JR, Dugdale R, Mackenzie N, Pownall R. Possible effect of time on renal allograft rejection. Br Med f 1979;i:75-7.

${ }^{3}$ Panayi GS, Corrigall V. Lymphocyte function in rheumatoid arthritis. In: Panayi GS, Johnson PM, eds. Immunopathogenesis of rheumatoid arthritis. Chertsey: Reedbooks Ltd, 1978:31-6.

${ }^{4}$ Nyedegger UE, Lambert PH. Complement activation in rheumatoid arthritis. In: Panayi GS, Johnson PM, eds. Immunopathogenesis of rheumatoid arthritis. Chertsey: Reedbooks Ltd, 1978:103-8.

${ }^{5}$ Scott JT. Morning stiffness in rheumatoid arthritis. Ann Rheum Dis 1960;19:361.

6 Wright V, Plunkett TG. Scientific assessment of the results of physical treatment-measurement of stiffness. Annals of Physical Medicine $1966 ; 8: 280$.

'Kowanko IC, Pownall R, Knapp MS, Swannell AJ. Circadian variations in the signs and symptoms of rheumatoid arthritis and in the therapeutic effectiveness of flurbiprofen at different times of day. Brf Clin Pharmacol $1981 ; 11: 477-84$

${ }^{8}$ Smolenzky MH, Reinberg A, McGovern JP. Recent advances in the chronobiology of allergy and immunology. Oxford: Pergamon Press, 1980.

${ }^{9}$ Ropes MW, Bennett GA, Cob S, Jacox R, Jessar RA. Revision of diagnostic criteria in rheumatoid arthritis. Bull Rheum Dis 1959;9:175-6. 
${ }^{10}$ Ritchie DM, Boyle JA, McInnes JM, et al. Clinical studies with an articular index for the assessment of joint tenderness in patients with rheumatoid arthritis. $Q \mathcal{F}$ Med 1968;27:393-406.

11 Mancini G, Carbonara AO, Heremans JF. A single radial diffusion method for the immunological quantitation of proteins. In: Peeters $\mathrm{H}$, ed. Protides of biological fluids, 11th colloquium, Bruges. Oxford: Pergamon Press, 1963:370.

12 Zubler RH, Lange G, Lambert PH, Miescher PA. Detection of immune complexes in unheated sera by modified ${ }^{125} \mathrm{I}-\mathrm{Clq}$ binding test. $\mathcal{F}$ Immunol 1976;116:232.

${ }^{13}$ Gripenberg M, Wafin F, Isomaki H, Linder E. A simple enzyme immunoassay for the demonstration of rheumatoid factor. $f$ Immunol Methods $1979 ; \mathbf{3 1}: 109$

14 Mattingly D. A simple fluorimetric method for the estimation of free 11-hydroxycorticosteroids in human plasma. F Clin Pathol 1962;15: 374-9.
15 Nelson W, Tong YL, Halberg F. Methods for Cosinor-rhythmometry. W Chronobiologia 1979;6:305.

${ }^{16}$ Fauci AS. Glucocortocoid therapy: mechanism of action and clinical considerations. Ann Intern Med 1976;84:304-15.

17 Pownall R, Knapp MS. Immune responses have rhythms, are theyc important ? Immunology Today 1980;October:vii-x.

18 Pownall R, Knapp MS. Chronobiologic evaluation of hypersensitivity reactions and the influence of circadian variations in endogenous corticosteroid. Allergologie 1980;3,suppl 4:S231-6.

19 Clench J, Reinberg A, Dziewanoska J, Ghata J, Dupont J. Chronopharmacokinetics of indomethacin in nine healthy young human adults. Chronobiologia 1977;4:105.

2" Knapp MS, Pownall R. Chronobiology, pharmacology and the immune system. International fournal of Immunopharmacology 1980;2:91-3.

(Accepted 26 November 1981)

\title{
Community care compared with hospital outpatient care for hypertensive patients
}

\author{
C J BULPITT, M J DAYMOND, C T DOLLERY
}

\begin{abstract}
Three hundred and seventy-six patients with treated diastolic blood pressures of less than $105 \mathrm{~mm} \mathrm{Hg}$ and no history of accelerated hypertension or renal failure were selected from among those attending the Hammersmith Hospital hypertension clinic. Their average lying treated blood pressure was $146 \mathrm{~mm} \mathrm{Hg}$ systolic and $90 \mathrm{~mm} \mathrm{Hg}$ diastolic and average age 56 years; $18 \%$ were black, $6 \%$ Asian, and $76 \%$ white. The patients were mostly having multiple treatment, $90 \%$ receiving a diuretic, $35 \%$ methyldopa, $33 \%$ propranolol, $18 \%$ atenolol, $9 \%$ hydrallazine, and $7 \%$ bethanidine. They were randomly allocated to either two years of further hospital outpatient care or referred back to their general practitioners.

During the two years $19(10 \%)$ of the 187 patients followed up in hospital defaulted and three had their treatment discontinued. Twelve $(6 \%)$ of the 189 followed up by their general practitioners defaulted from followup and nine had their treatment discontinued. At the end of the trial the average lying blood pressure was 148 $\mathrm{mm} \mathrm{Hg}$ systolic and $88 \mathrm{~mm} \mathrm{Hg}$ diastolic in the hospital group and $149 \mathrm{~mm} \mathrm{Hg}$ systolic and $90 \mathrm{~mm} \mathrm{Hg}$ diastolic in the general practice group. The change in blood pressure was calculated for each individual and showed an average fall of $1.6 \mathrm{~mm} \mathrm{Hg}$ in standing diastolic pressure in the hospital group and a rise of $1.4 \mathrm{~mm} \mathrm{Hg}$ in the general practice group $(p<0.05)$. The $90 \%$ confidence limits for a difference in standing diastolic pressure between the groups were 1 and $5 \mathrm{~mm} \mathrm{Hg}$ with the pressure lower in the hospital group.

General practice care was not quite as effective in controlling blood pressure as continued specialist supervision over two years in this selected group of treated outpatients with mild or moderate hypertension, but
\end{abstract}

\footnotetext{
Department of Clinical Pharmacology, Royal Postgraduate Medical School, London W12

C J BULPITT, MD, MSC, honorary senior lecturer

$M$ J DAYMOND, research assistant

C T DOLLERY, MB, FRCP, professor
}

these results show that the discharge back to general practitioners of patients who are well controlled after $\bigcirc$ hospital treatment is a sensible policy.

\section{Introduction}

It is important to determine whether or not patients receiving! antihypertensive medication need to be followed in a specialist hospital-based outpatient clinic or whether they can be dis-charged to the care of their general practitioner. A recent survey found that general practitioners tend to use as wide a range ofg antihypertensive drugs as the hospital based clinics but used these agents in smaller doses and thus achieve less good blood pressure control. ${ }^{1}$ When good blood pressure control is obtained? in a hospital clinic, however, the general practitioners may be able to continue this process, with a saving in costs and at reduction in the distances travelled by the patients. We therefore report a randomised controlled trial which examined whethers blood pressure control was better or worse when patients continued to attend a specialist hospital clinic than when they were referred back to the care of their general practitioners.

\section{Patients and methods}

Patients attending the Hammersmith Hospital hypertension follow up clinic were entered into the trial if they fulfilled the following criteria: a lying or standing diastolic blood pressure of $104 \mathrm{~mm} \mathrm{Hg}$. or less (point of muffling of the sound) on the day of randomisation and at the preceding clinic visit; no history of malignant or accelerated hypertension; plasma urea concentration never greater than 9.96 $\mathrm{mmol} / \mathrm{l}(59.6 \mathrm{mg} / 100 \mathrm{ml})$; and no co-existent disease requiring continued hospital surveillance. The patients had been followed in the clinic and given antihypertensive treatment for periods rangings from a few months to several years.

When the patients gave verbal consent they were randomised to continued hospital outpatient care or for referral back to their genera practitioner. All patients were given a booklet about hypertension and a card indicating their current treatment and blood pressure. They were asked to present the card for completion whenever their bloods pressure was taken or treatment changed either by the clinic or by their general practitioner.

When a patient was randomised for referred care a letter was sent to the general practitioner stating the aims of the trial and the face 